\title{
The early bee catches the flower - circadian rhythmicity influences learning performance in honey bees, Apis mellifera
}

\author{
Marina Lehmann • David Gustav • C. Giovanni Galizia
}

Received: 28 January 2010 /Revised: 12 July 2010 /Accepted: 14 July 2010 /Published online: 31 July 2010

(C) The Author(s) 2010. This article is published with open access at Springerlink.com

\begin{abstract}
Circadian rhythmicity plays an important role for many aspects of honey bees' lives. However, the question whether it also affects learning and memory remained unanswered. To address this question, we studied the effect of circadian timing on olfactory learning and memory in honey bees Apis mellifera using the olfactory conditioning of the proboscis extension reflex paradigm. Bees were differentially conditioned to odours and tested for their odour learning at four different "Zeitgeber" time points. We show that learning behaviour is influenced by circadian timing. Honey bees perform best in the morning compared to the other times of day. Additionally, we found influences of the light condition bees were trained at on the olfactory learning. This circadian-mediated learning is independent from feeding times bees were entrained to, indicating an inherited and not acquired mechanism. We hypothesise that a co-evolutionary mechanism between the honey bee as a pollinator and plants might be the driving force for the evolution of the time-dependent learning abilities of bees.
\end{abstract}

Keywords Circadian $\cdot$ Honey bee $\cdot$ Learning $\cdot$ Olfaction

Communicated by M. Giurfa

Electronic supplementary material The online version of this article (doi:10.1007/s00265-010-1026-9) contains supplementary material, which is available to authorized users.

M. Lehmann · D. Gustav • C. G. Galizia $(\bowtie)$

Neurobiology, University of Konstanz,

Universitätsstraße 10,

78464 Konstanz, Germany

e-mail: giovanni.galizia@uni-konstanz.de

\section{Introduction}

With the constant recurrence of day and night, animals are faced with changes in light, temperature and other environmental factors such as food or predators. The steady quality of this phenomenon itself gives them the possibility to anticipate and to exploit the right time of day and situation. Prediction of the changes in environment is made possible by the endogenous circadian clock. Circadian rhythmicity affects nearly every aspect of animal or human life, from the cellular level up to behaviour. So, it is no surprise that learning also has been shown to be affected by diurnal rhythms (Daan 2000; Schmidt et al. 2007).

The existence of diurnal rhythmicity for honey bees was already noticed at the beginning of the twentieth century when Hugo von Buttel-Reepen (1900) showed that bees are able to learn the time of day when flowers produce nectar and pollen. Ten years later, Forel (1910) described bees harvesting at his breakfast table every day at the same time of day. This memory of time was termed "Zeitgedächtnis" and extensively studied by Beling (1929) and Wahl (1932). At that time, it was hypothesised that the "Zeitgedächtnis" is somehow related to the nectar and pollen secretion of the flowers bees forage on (Beutler 1930; Kleber 1935) and that bees only forage when the secretion reaches its daily maximum.

A strong indication that honey bees have an endogenous sense of time was given by Renner (1960) with a transoceanic experiment in which he flew timeentrained bees from Paris to New York and observed that the bees still maintained their Paris time schedule. Beier and Lindauer (Beier 1968; Beier and Lindauer 1970) showed that the circadian rhythm is adjusted daily by the sun as the "Zeitgeber", and Koltermann (1971) showed that the "Zeitgedächtnis" lets the bees distinguish between 
time points as close as $20 \mathrm{~min}$ and is not restricted to odours but also applicable to colours. Prabhu and Cheng (2008a, b) demonstrated that this ability functions even after only 1 day of learning for both modalities and despite impairment by conflicting memories. Later on, the genetic background of the honey bee circadian clock was unravelled (Toma et al. 2000; Rubin et al. 2006) based on findings in other insect species beginning in 1971 with the discovery of the period gene in Drosophila melanogaster (Konopka and Benzer 1971).

Most experiments concerning the behavioural and ecological aspects of circadian rhythmicity in honey bees were made at population level, with few exceptions (Moore and Rankin 1983; Kaiser 1988). All experiments were conducted to elucidate the ability to remember a specific time of the day or to find other possible "Zeitgeber" that would add to the role of daylight. So far, no study investigated whether the bees' learning performance varies with a circadian rhythm. This is surprising, given that memory has been shown to be modulated by circadian time in other species, such as the cockroach Leucophaea maderae (Decker et al. 2007), the fruit fly D. melanogaster (Lyons and Roman 2009) and the molluscs Aplysia californica and Aplysia fasciata (Lyons et al. 2005). The influence of the circadian clock on memory has also been shown in vertebrates such as zebrafish (Rawashdeh et al. 2007) or humans (Fabbri et al. 2008). Therefore, we investigated the influence of circadian timing on the learning performance of individual honey bees using the proboscis extension reflex (PER) (Bitterman et al. 1983) for appetitive differential conditioning (see "Materials and methods") at several times of the day and found that learning performance is best in the morning. We then investigated whether this daily performance peak can be shifted by entraining the bees to specific food expectations at other times of the day and found this not to be the case.

\section{Materials and methods}

\section{Honey bees}

All experiments were conducted on Apis mellifera foragers (nurses do not show circadian rhythmicity (Shemesh et al. 2007)). Bees were captured either at a feeder placed in front of the hives, at the entrance of the hive or, in case of the indoor bees, at the hive surrounding gauze. Bees not caught at the feeder were identified as foragers by their advanced age (behaviourally by catching bees flying or sitting outside the hive and by their overall appearance, e.g. loss of thoracic hair, darker abdomen, worn-out wings). The bees were cooled on ice for several minutes until they just stopped moving. We kept cooling time as short as possible in order to minimise possible effects on circadian timing, given that temperature is a potent "Zeitgeber" (Fuchikawa and Shimizu 2007). Cooling time was always below $10 \mathrm{~min}$ and thus much less than the $30 \mathrm{~min}$ reported to have an effect on circadian rhythmicity (Hamm et al. 1975).

After harnessing, bees were fed with $1.25 \mathrm{M}$ sucrose solution ad libitum. All bees stayed overnight or, in case they were conditioned at night, over the day either in their container or in a humidified environment in an undisturbed room. For the harnessed outdoor bees, it was assured that they experienced normal daily rhythmicity during that time, i.e. day length and temperature. All experiments took place between February and September.

\section{Outdoor bees}

Bees originating from outdoor hives could fly freely in the surrounding area and forage in the nearby meadows and woods. Outdoor bees experienced the normal periodicity of the day length, the naturally occurring changes in temperature and wind conditions and the natural succession of blooming and nectar flow.

\section{Indoor bees}

Indoor bees were kept in a gauze cage $(4 \times 2.4 \times 2.3 \mathrm{~m})$ within a room $(6 \times 2.40 \times 2.50 \mathrm{~m})$. These rooms were illuminated by 12 fluorescent tubes (Philips Master TL-D90 DeLuxe Pro 58 W/965) and 12 UV-fluorescent tubes (Osram Eversun L80/79). Electronic ballasts enhanced the tubes' flickering rate to $300 \mathrm{~Hz}$. Temperature and humidity were controlled with an electric heater and an air humidifier. Humidity was set to approximately $75 \% \mathrm{RH}$; temperature was kept between $18^{\circ} \mathrm{C}$ (night) and $25^{\circ} \mathrm{C}$ (daytime). Solar radiation and high external temperatures led to slightly higher temperatures during some summer days. The luminance $1 \mathrm{~m}$ above the ground was approximately $1,800 \mathrm{~lx}$. Sugar water, ground pollen and water were provided on a table where the bees could forage. According to the experimental needs, the light dark cycle was either $12 \mathrm{~h}$ light/12 h darkness (LD) or 12:12 DL. These bees will be referred to as indoor bees.

\section{Differential PER conditioning}

At 10 min before the experiments, each bee was checked for intact PER by slightly touching one antenna with $1.25 \mathrm{M}$ sucrose solution without feeding the bee. Animals that did not show any reflex or could not move their 
mouthparts freely were excluded from the experiments. Additionally, bees which showed no response at all during training and test were excluded from the analysis as well as bees which responded to each odour constantly.

An appetitive differential conditioning was used to analyse olfactory learning. One odour served as a reinforced conditioned stimulus $(\mathrm{CS}+)$, it was rewarded with $1.25 \mathrm{M}$ sucrose solution (unconditioned stimulus, US); the other odour remained unrewarded (CS-) (Bitterman et al. 1983). The odours were delivered to the honey bees using a custom-built, computer-controlled olfactometer. Air velocity at the bees head was about $1.6 \mathrm{~m} / \mathrm{s}$ consisting of a carrier airstream and an odour stream. To avoid changes in air velocity, opening the odour stream was compensated by closing a corresponding air stream. For all experiments, 1hexanol and 2-octanol (Sigma Aldrich) were used. These odours were diluted $10^{-2}$ in mineral oil. A total of $200 \mu \mathrm{l}$ of the diluted odour was applied on rectangular Sugi strips (Kettenbach $\mathrm{GmbH} \& \mathrm{Co}$. KG, Eschenburg, Germany) and placed at the distal end of 2-ml syringes in the olfactometer. Air suction behind the conditioning apparatus prevented the odours from accumulating.

An intertrial interval of $10 \mathrm{~min}$ and a trial duration of $40 \mathrm{~s}$ allowed training of 15 bees in parallel. After $20 \mathrm{~s}$ of familiarisation to the experimental context, the CS was presented to the bee for $4 \mathrm{~s}$. Three seconds after onset of the $\mathrm{CS}+$, the antennae were stimulated with the US, leading to a proboscis extension. The bee was allowed to feed for $3 \mathrm{~s}$. The bee was left in the conditioning context for an additional $14 \mathrm{~s}$.

The bees were exposed to a total of 12 odour stimuli during training. The odours were presented in a pseudorandomised order (e.g. ABBABAABABBA) starting with odour A or B in a balanced presentation. Both hexanol and octanol served as $\mathrm{CS}+$ in a balanced way. Thirty minutes after training, bees were tested for their odour response. The test procedure was similar to that for conditioning trials but no US was given after odour delivery. The test odours were applied in the order $\mathrm{CS}+-\mathrm{CS}-$.

During the experiments, the bee's response to the presented odorant (PER or no PER) after the onset of the odorant and before the presentation of the sugar water in the case of reinforced trials was recorded. Multiple responses during odorant presentation were counted as a single PER. The response to the odour alone was noted as 1; no response or PER triggered by sugar water were noted as 0. From the responses to the $\mathrm{CS}+$ and the $\mathrm{CS}^{-}$, a differential learning index (DLI) was calculated (Eq. 1).

2This index is a variant of previous discrimination indices (Pelz et al. 1997; Vergoz et al. 2007; Fernández et al. 2009). It corresponds to the difference between the CS+ response and the CS- response (compare Fig. 2b and c). Mathematically, it is calculated as

$$
\mathrm{DLI}=\frac{n_{1}-n_{\mathrm{n}}}{n_{\mathrm{t}}}
$$

where $n_{1}$ is the number of learning bees (response to CS+, but not to $\mathrm{CS}^{-}$), $n_{\mathrm{n}}$ the number of non-learning bees (no response to $\mathrm{CS}+$ but to $\mathrm{CS}^{-}$) and $n_{\mathrm{t}}$ the total number of bees.

\section{Experimental design}

To investigate the impacts of diurnal rhythmicity on learning performance, it was necessary to train the bees at fixed daily time points. Standard illumination regime for indoor bees was $12 \mathrm{~h}$ light and $12 \mathrm{~h}$ darkness (12:12 LD) with lights on at 07:00 ("Zeitgeber" time (ZT0)) and lights off at 19:00 (ZT12) (Fig. 1a). Additionally, there was a

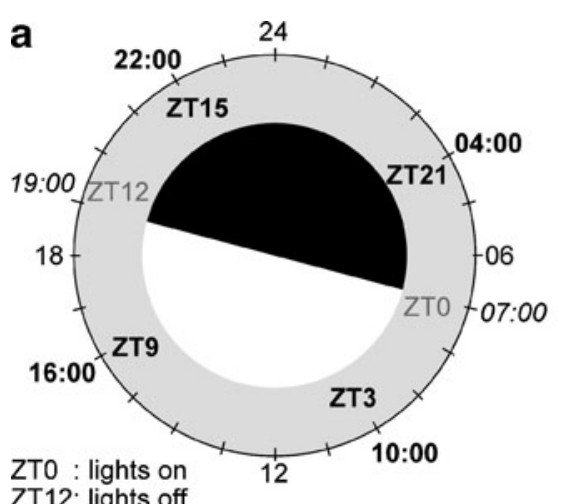

ZT12: lights off

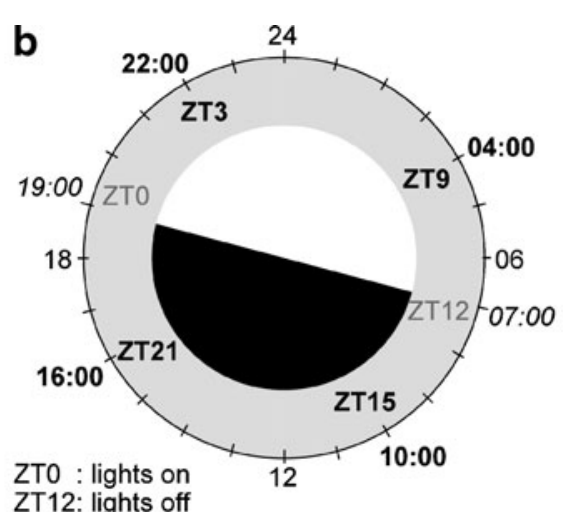

ZT12: lights off
Fig. 1 Relationship of illumination, real time and "Zeitgeber" time for the different bees. The inner circle indicates the illumination regime (black - darkness, white - daylight); the outer circle the "Zeitgeber" time. At the circles' outside, the corresponding time of day can be found. a Indoor bees (12:12 LD). Both night and day are of equal length $(12 \mathrm{~h})$. Light is switched on at 07:00 (ZT0) and switched off at 19:00 (ZT12) - indicated by italic times. b Inverted indoor bees

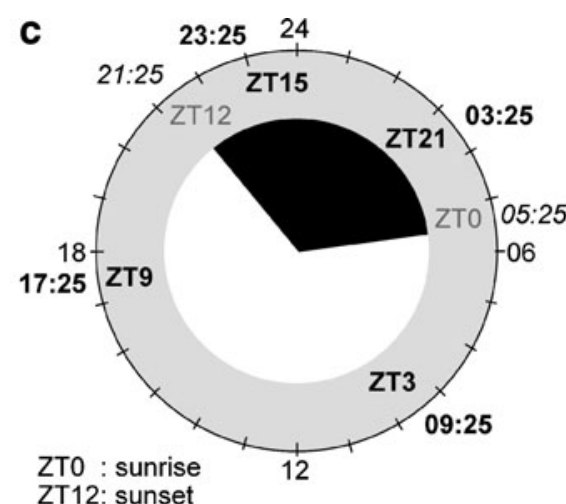

(12:12 DL). Both night and day are of equal length $(12 \mathrm{~h})$. Light is switched on at 19:00 (ZT0) and switched off at 07:00 (ZT12) indicated by italic times. c Outdoor bees at mid-June (21.06) with a day length of $16 \mathrm{~h}$ and a night length of $8 \mathrm{~h}(16: 8)$. Sunrise in this example is at 05:25 (ZT0) and sunset at 21:25 (ZT12) - indicated by italic times 
12:12 regime with inverted illumination (referred as 12:12 DL in the following text) leading to ZT0 at 19:00 and ZT12 at 07:00 (Fig. 1b). Training times were set to ZT3, ZT9, ZT15 and ZT21, corresponding to one quarter and three quarters of day and night, respectively.

The illumination for indoor bees was also inverted to control for possible effects resulting from other "Zeitgeber" than light (e.g. vibrations of the building during daytime, traffic noise, etc.).

For outdoor bees, time points were chosen with respect to sunrise, i.e. appearance of the sun above the horizon as equivalent of lights on. Sunrise was set as ZT0 and sunset as ZT12, irrespective of the actual day length, using public databases (GeneralAviation 2009; Thiele 2009) as source of correct time for Konstanz, Germany. Because the photoperiod changes throughout the year for the outdoor bees, these time points had to be adjusted (Fig. 1c), i.e. training times were defined in relationship to total day length. For an overview of the different trainings and testing times with respect to the different treatments and ZTs, see tables S1 and S2.

Because illumination is an important "Zeitgeber", light conditions during the experiments might influence the results. We therefore trained and tested both in light (daylight) and darkness (dim red light) at all time points.

\section{Bees in constant darkness}

Circadian rhythmicity is maintained without a "Zeitgeber" in both constant light (Frisch and Aschoff 1987) as well as constant darkness (Moore and Rankin 1985) for some time. To evaluate whether our findings are of a real circadian nature, we kept outdoor bees in constant darkness and constant temperature for about 2 days and trained them at the same time points as described above using the same experimental context. The bees were caught in front of an outdoor hive and kept in a $30 \times 30 \times 30 \mathrm{~cm}$ insect rearing cage (BUGDORM-1, MegaView Science Education Services Co., Taiwan) inside a completely dark room lightened by dim red light only during preparation of the bees. Bees were caught inside the rearing cages, cooled on ice for several minutes until they stopped moving and harnessed $3 \mathrm{~h}$ prior to the experiment. After harnessing, the bees remained in the dark room until the start of the conditioning.

We adjusted the duration of the single experiment by decreasing the intertrial interval to $5 \mathrm{~min}$. The number of training trials remained the same and the odour exposure time for each bee remained the same, but the familiarisation time within the airstream prior to the odour exposure and after the odour exposure was decreased. Bees were tested $30 \mathrm{~min}$ after the last training trial. Bees were trained and tested both in light (daylight) and darkness (dim red light) at all time points. Because no differences concerning the odours were found previously, we only used octanol as CS+ for these experiments.

Feeding

To evaluate the impact of feeding time on learning performance, outdoor bees were trained to two feeding stations next to the hives. The feeding stations were odorised by a mixture of 1-hexanol, 2-octanol, linalool and limonene (Sigma Aldrich; Merck, Darmstadt, Germany) and were accessible to the bees either at ZT3 or at ZT9. Bees were caught at the feeders 1 day prior to the experiment and treated like the other bees. They were conditioned at ZT3 or ZT9 and their differential learning index was calculated.

Additionally, two hives were transferred into two cages with a diameter of $4 \times 2 \times 2.50 \mathrm{~m}$ and situated outdoors. These semi-outdoor bees were subject to the normal diurnal rhythmicity and normal weather conditions. Two feeding devices were placed in front of the hive. They were accessible at either ZT3 (9:00 - 12:00) or ZT9 (16:00 - 19:00) for 1 week prior to the experiments and during the experiments. Bees were caught at these feeding devices, cooled on ice and harnessed 1 day prior to the experiment and then underwent differential conditioning as described above on ZT3 and ZT9.

\section{Meta-analysis of pollen and nectar data}

We analysed data provided by several studies (Kleber 1935; Percival 1947, 1950; Maurizio 1953; Pesti 1976; Mačukanović and Blaženčić 1998) with respect to temporal patterns of both nectar and pollen secretion. Because these studies used several different methods, we normalised these data concerning the number of plants secreting nectar or pollen for each hour of day. A paper stating, for example, "pollen for plant X between 8 and 10" resulted in counting one species of plants secreting pollen at 8, 9 and 10. All 86 plants used to calculate the pollen secretion are known as important food sources for bees as well as most of the 49 plants providing information on nectar secretion (see online resources tables S3 and $\mathrm{S} 4$ ) .

\section{Statistics}

The percentage of PER recorded during acquisition was used to plot learning curves. To analyse the variation of performance during trials, we used analyses of variance (ANOVAs). It has been shown that it is permissible to use ANOVA on dichotomous data when there are at least 40 degrees of freedom (Lunney 1970; Guerrieri et al. 2005). These conditions were met by all experiments. When appropriate, $t$-tests were used. Analyses were performed using the "R" software ( $R$ 
Development Core Team 2008; http://www.R-project.org), Statistica 6.1 (StatSoft Europe GmbH, Hamburg, Germany) and JMP (SAS Institute GmbH, Heidelberg, Germany).

\section{Results}

In total, we trained 1,155 honey bees along six trials at four different "Zeitgeber" time points in order to evaluate their learning performance at different times of day. Out of the total number of 1,155 bees, 366 were outdoor bees and 789 were indoor bees. Additionally, we trained 169 bees as a control in constant darkness (DD) and we trained 352 bees in order to evaluate the influence of food supply on diurnal learning performance.

\section{Differential conditioning}

Odour learning acquisition During training, we measured the learning acquisition curve. Figure 2 a shows a typical acquisition curve (additional curves are given in online resource S5). The mean initial PER response towards the odours at trial one was $21 \%$. In all experiments, some animals responded spontaneously to the odour on the first trial, which is normal for PER experiments (Menzel 1990). Response to the CS+ increased strongly during the following trials. Bees also responded to the $\mathrm{CS}-$ during the first trials (odour generalisation). The training curves began to diverge during the course of the experiments, indicating that bees learned to discriminate $\mathrm{CS}+$ and $\mathrm{CS}-$. Responses to the last trial for the CS+ ranged between $75 \%$ and $84 \%$ and for the CS- between $18 \%$ and $29 \%$ of possible $100 \%$, respectively; there was a significant difference in this last acquisition trial between $\mathrm{CS}+$ and CS- in all groups (repeated measurements analysis of variance (RM-ANOVAs), $P<0.05$; for Fig. $2 \mathrm{a}, F_{1}, 96=$ 170.5186, $P<0.0001)$.
Test Bees were tested 30 min after training. During the test phase, the responses to the CS+ corresponded approximately to those of the last training trial. The responses to the $\mathrm{CS}+$ ranged between $78 \%$ and $83 \%$ and were always higher than those to the $\mathrm{CS}-$, which ranged between $19 \%$ and $32 \%$ (see also online resource S6; for Fig. 2b, $F_{1,96}=$ 155.6757, $P<0.0001)$. The difference was significant in all groups (RM-ANOVAs, $P<0.001$ ). There was no significant difference between the odours used as $\mathrm{CS}+$; the responses towards octanol as well as to hexanol were equal (one-way ANOVA, $\left.F_{1,1153}=3.4005, P=0.0654\right)$.

Differential learning index The responses towards the CS+ and the $\mathrm{CS}-$ measured during the test were used to calculate a DLI (see "Materials and methods") in order to evaluate the learning performance under different conditions. Figure $2 \mathrm{c}$ shows the differential learning index corresponding to Fig. 2b. Higher DLI correspond to a higher discrimination ability of the honey bees which is our definition of learning performance.

Influence of "Zeitgeber" time on learning performance

Learning performance as measured with DLI varied at different times of day and night (Fig. 3). A comparison of DLI at the four different ZTs for outdoor bees (Fig. 3a), indoor bees (Fig. 3b) and bees maintained under constant darkness (Fig. 3c) showed that bees learn significantly better at ZT3 than at all other ZTs in all groups (with exception for the comparison ZT3 with ZT21 in Fig. 3c) (one-way ANOVA, $F_{3}, 1319=14.3624, P<0.0001$; Fisher post-hoc comparison, ZT3/ZT9 $P<0.0001$, ZT3/ZT15 $P<$ $0.0001, \mathrm{ZT} 3 / \mathrm{ZT} 21, P=0.0004$; outdoor bees $F_{3}, \quad 362=$ 5.4057, $P=0.0012$; Fisher post-hoc comparison, ZT3/ZT9 $P=0.0145, \mathrm{ZT} 3 / \mathrm{ZT} 15 P=0.0001, \mathrm{ZT} 3 / \mathrm{ZT} 21 P=0.0045$; indoor bees $F_{3}, 785=6.3439, P=0.0003$; Fisher post-hoc
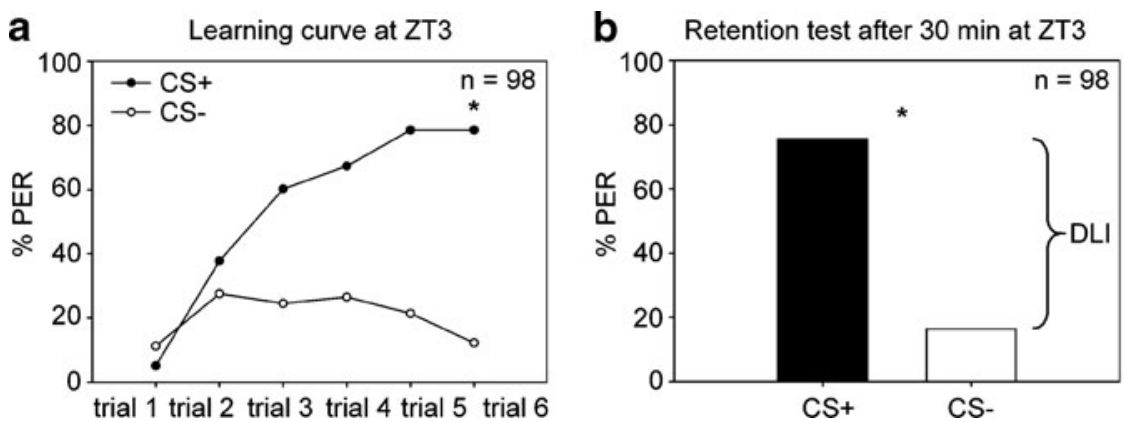

Fig. 2 Differential conditioning of honey bees and calculation of differential learning index DLI. a Typical acquisition curve. Full circles, proboscis extension reflex (PER) response to conditioned stimulus (CS)+; empty circles, PER response to CS-, total of six training trials. b
PER response to $\mathrm{CS}+$ and $\mathrm{CS}-30 \mathrm{~min}$ after the last trial. The learning performance was calculated from the difference between the two bars (see text). $\mathbf{c}$ Example of differential learning index (DLI) for data of $\mathbf{b}$. Asterisks indicate significant differences (see text)

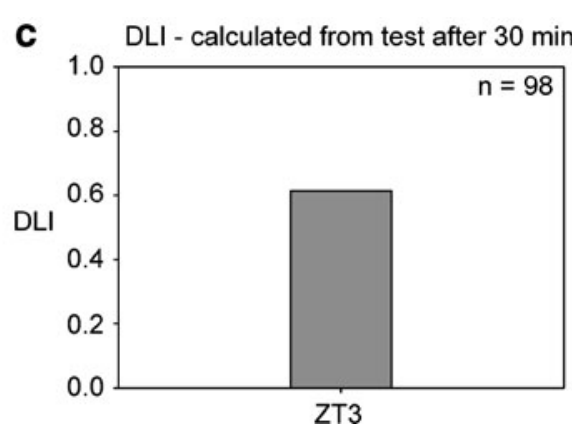



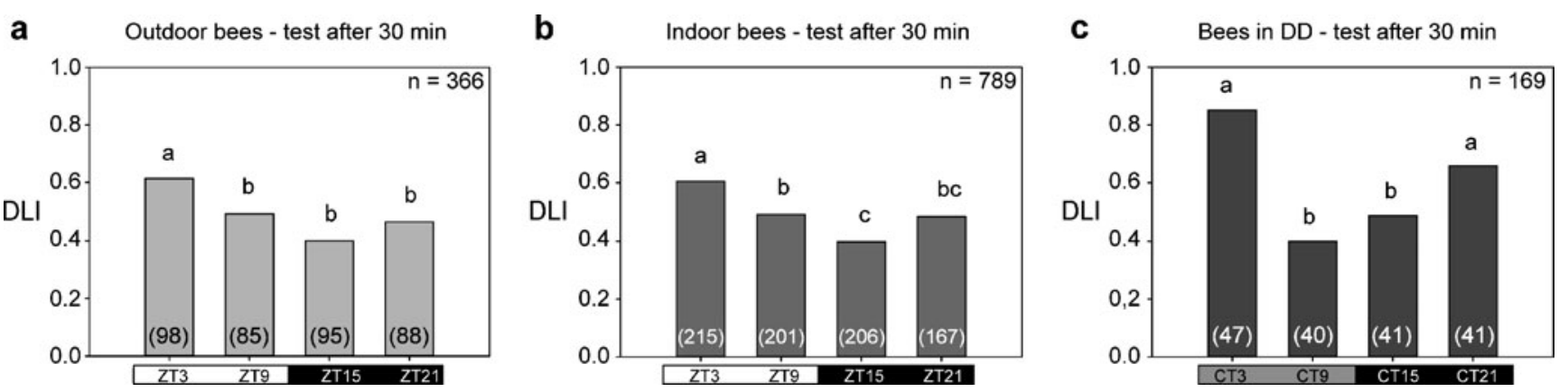

Fig. 3 Learning performance is better at ZT3 than at all other "Zeitgeber" time points. a Outdoor bees, differential learning indices (DLI) at four different "Zeitgeber" time points (ZTs). b Indoor bees in artificial day-night rhythm. c Outdoor bees that were kept in constant darkness for 2 days prior to training. Horizontal bars: white bar,

training and testing during day; black bar, training and testing during night; grey bar, training and testing during subjective day. In all cases, DLI at $30 \mathrm{~min}$ post-training are shown. Letters indicate statistical difference (see text), numbers in brackets indicate sample sizes

comparison, ZT3/ZT9 $P=0.0226$, ZT3/ZT15 $P<0.0001$, ZT3/ZT21 $P=0.0151$ ). There were no significant differences between the three treatments, showing that the good performance at ZT3 is a robust phenomenon.

Our experiments were balanced with respect to the odour used for CS+ (two groups), i.e. both odours were used as CS+ and $\mathrm{CS}^{-}$, respectively, to exclude possible innate odour preferences and with respect to the illumination regime for training and testing (i.e. every experiment was conducted either in the dark or with light). There was no interaction for DLI between ZT and the odour used as CS+, and the effect of odour was not significant (two-way-ANOVA, odour $\times \mathrm{ZT}, F_{3}$, ${ }_{1147}=1.778, P=0.3170$; odour alone, $P=0.1097$; online resource $S 7 b$ ). Equally, there was no interaction between the state of illumination and ZT (two-way-ANOVA, light $\times \mathrm{CT}$, $\left.F_{3,1147}=0.4218, P=0.7374\right)$. However, testing in the dark or with light had a strong influence on test performance: bees performed better in the dark (one-way ANOVA, $F_{1,1153}=$ 16.4018, $P<0.0001$; online resource $\mathrm{S} 7 \mathrm{a})$.

\section{Bees in constant darkness}

When a circadian rhythm is deprived of its "Zeitgeber" (e.g. light, since in most cases the sun is the most important "Zeitgeber"), it will generally continue on its own in a free-running rhythm, though the phase will shift and rhythm amplitude will be reduced (Aschoff 1981). To test whether the better learning performance that we observed at ZT3 relies on an endogenous circadian rhythm, we trained bees that were kept in DD. In constant darkness bees, DLI was also higher in the morning (CT3) than in the afternoon (CT9) (one-way ANOVA, $F_{3}, 165=9.5523, P<0.0001$; Fisher post-hoc comparison, $P<0.0001$ ). Hence, better learning performance in the morning is truly circadian and controlled endogenously.
Influence of feeding time on DLI

Though controlled endogenously, learning performance during the day could be additionally influenced by individual feeding experience. Since the first observations of circadian rhythmicity in honey bees, it was hypothesised that foraging activity is synchronised with flower rhythmicity, in particular with diurnal fluctuation in nectar and pollen availability. Bees easily learn to associate a specific time of the day with a food source and its remaining parameters, such as location, odour and visual display (Pahl et al. 2007; Prabhu and Cheng 2008a; Prabhu and Cheng 2008b). Furthermore, many flowers in temperate zones secrete more nectar and pollen early in the day (Kleber 1935; see also Fig. 4, this paper). Thus, better learning performance in the morning may well be linked to so-called food anticipatory activity (Moore and Doherty 2009) reflecting the individual experience of each bee as it has been shown that bees are more precise in arriving at a specific time and food source (Moore and Rankin 1983; Moore et al. 1989). We therefore tested the influence of food availability for the hive on the learning behaviour of bees. Outdoor bees were trained to sugar water feeders whose attractiveness to the bees was reinforced with an odour mixture. Within a few days, bees showed up at the feeding place about a quarter of an hour earlier, confirming the often described food anticipation behaviour (von Frisch 1965; Moore et al. 1989; Moore and Doherty 2009). Bees from these feeders were then used in our training assay. Bees from hives entrained to food at ZT3 learned significantly better at ZT3 than at ZT9 $\left(F_{1}, 86=4.7953, P=0.0312\right.$; Fig. 4a). However, also bees from hives entrained to food at ZT9 had higher DLI at ZT3 than at ZT9 $\left(F_{1,84}=29.9065\right.$, $P<0.0001$; Fig. 4a). A two-way ANOVA showed that food entrainment of the hive had no influence on DLI values $\left(F_{1}\right.$, $\left.{ }_{170}=0.2212, P=0.6388\right)$, while the difference between ZT3 and ZT9 was significant $\left(F_{1,170}=26.4638, P<0.0001\right)$. It 
a

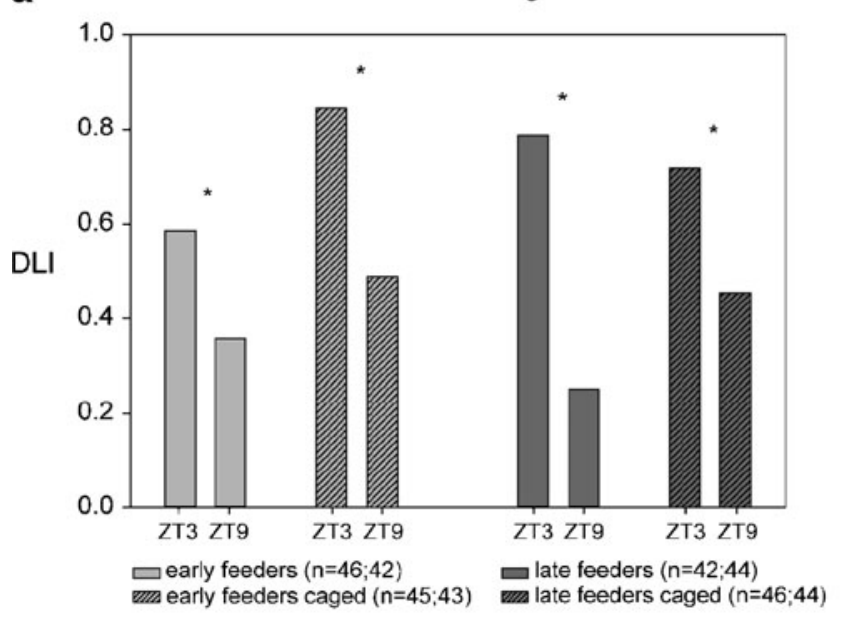

Fig. 4 Better learning performance at ZT3 is maintained irrespective of feeding time. a Feeding time does not influence the learning performance of honey bees. Learning performance at "Zeitgeber" time (ZT) 3 is significantly higher than at ZT9 for both early feeders (bees had access to food at ZT3) as well as late feeders (bees had access to food at ZT9) in both treatments (free $(n=174)$ and caged $(n=178)$ bees). Asterisks indicate significant difference (see text). b Plants

should be noted, however, that there was some interaction between $\mathrm{ZT}$ and feeding time (ZT $\times$ feeding time, $F_{1,170}=$ 5.2292, $P=0.0234)$.

Although there were almost no nectar-secreting plants in bloom during the duration of these specific experiments (August in Southern Germany), it could not be excluded that other food sources might have been used by the bees and that these might have influenced the bees' experiences. Therefore, the experiments were repeated with semioutdoor bees. Here, hives were kept in outdoor cages so that they experienced the same environment as outdoor bees, with the exception of available food sources that were entirely controlled in the experiment. By running different feeding times in parallel, we further reduced the influence of other parameters on our experiment. Bees learned to anticipate feeding and arrived early at the feeding place after a few days of regular feeding. In addition, we observed that flight activity in the cages was highest before, during and after feeding time, but less during the rest of the day. This happened independently of other factors such as temperature or rainy weather. These observations are also consistent with previous studies (von Frisch 1940; Moore et al. 1989). The DLI was higher at ZT3 than at ZT9 both for bees entrained to food at ZT3 $\left(F_{1}\right.$, $\left.{ }_{86}=14.3953, P=0.0003\right)$ and for bees entrained to food at ZT9 $\left(F_{1}, 88=5.6200, P=0.0199\right.$; Fig. 4a). A two-way ANOVA showed a significant effect in DLI magnitude between testing at ZT3 and at ZT9 values $\left(F_{1,174}=18.6050\right.$, $P<0.0001)$ but not for food entrainment times $\left(F_{1,174}=\right.$ b Diurnal rhythmicity of pollen and nectar

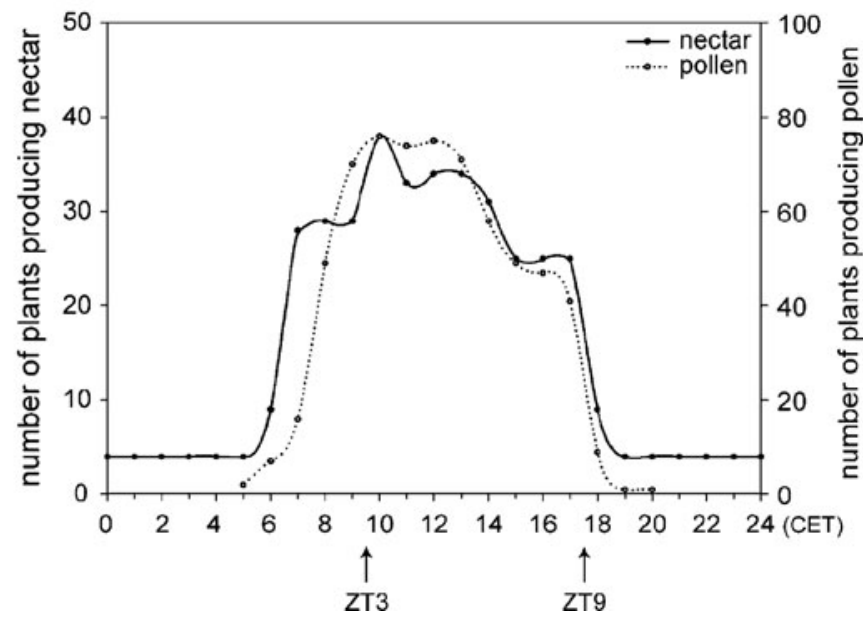

exhibit strong daily variation in nectar secretion and pollen production. The majority of nectar- and pollen-secreting plants blossom during the morning and early afternoon (meta-analysis based on data from Kleber (1935), Percival (1947, 1950), Maurizio (1953), Pesti (1976) and Mačukanović \& Blaženčić (1998); pollen: $n_{\text {plants }}=85$, nectar: $n_{\text {plants }}=44$ )

0.9990, $P=0.3189$ ) and no significant interaction between the two factors $\left(F_{1,174}=0.7038, P<0.4072\right)$.

\section{Discussion}

Bees learn better in the morning

In this study, we have investigated the influence of circadian rhythmicity on olfactory learning performance in honey bees and show that bees learn best in the morning.

Previous studies have shown that circadian rhythmicity has strong influences on various aspects of honey bees' lives. For instance, they use a time-compensated sun compass to navigate back and forth from the hive (von Frisch 1950; Lindauer 1960; von Frisch 1965) which they achieve by a combination of innate knowledge and an appropriate update depending on the situation (Dyer and Dickinson 1994; Towne 2008; Towne and Moscrip 2008), and their locomotor behaviour is driven by a circadian clock (Moore and Rankin 1985; Moore 2001). These findings show a clear diurnal variation in honey bees' activity. The foraging phase of honey bees is restricted to day light as their small and comparatively insensitive apposition compound eyes do not allow for foraging at night (Rose and Menzel 1981; Warrant et al. 1996). Furthermore, bees sleep in their inactive phase, especially at night (Kaiser 1988). So, it is no surprise that learning and memory in honey bees is better during the active phase, as 
it is in other species, e.g. cockroaches (Decker et al. 2007), A. californica and A. fasciata (Lyons et al. 2005), mice (Chaudhury and Colwell 2002) and humans (Kleitman 1933; Folkard 1975; Folkard and Monk 1980).

In addition, we find that, during the day, bees learn better in the morning as compared to the afternoon. This effect is clearly linked to the circadian rhythm. Our experiments, however, were not designed to evaluate the mechanistic origin of the effect. Thus, an effect of fatigue, of sleeping cycle, or of a direct link to the endogenous clock is possible, without being mutually exclusive. For example, sleep deprivation also affects memory, though its effect is complex with differences between acquisition and retention (Hussaini et al. 2009). The role of an endogenous rhythm is evidenced by our finding that bees kept in constant darkness also learn better in the morning. In addition, these bees showed no statistically significant difference between CT3 (morning) and CT21 (before dawn; Fig. 3c), suggesting a cycle time of less than $24 \mathrm{~h}$. Previous studies showed that the intrinsic day of bees is shorter than $24 \mathrm{~h}$, both for foraging rhythms (Bennett and Renner 1963; Beier 1968) and for locomotor behaviour (Moore and Rankin 1985). Further experiments with longer periods of darkness, a better temporal resolution and molecular manipulations are necessary to investigate the mechanistic origin of why learning is better in the morning.

\section{Bees learn better in darkness}

Additionally to our data concerning the influence of circadian timing on honey bee olfactory discrimination learning, we show that the experimental context is also important: bees learn to discriminate two odours remarkably better in darkness than under light. Possibly, it is just the effect of reduced distracting optical stimuli. Alternatively, or additionally, this might originate from honey bee biology: most of a bee's life takes place inside the dark hive where odours are a main source of information, including communication between workers and brood (Pankiw et al. 1998; Pankiw 2004; Sagili and Pankiw 2009) as well as the queen and the workers (Winston and Slessor 1992; Hoover et al. 2003; Pankiw et al. 2004). Additionally, odours are used by homing foragers to advertise profitable food sources (Farina et al. 2005; Arenas et al. 2007; Farina et al. 2007). Thus, the better learning performance for olfactory cues in darkness (irrespective of the time of day) could be an adaptation to living within the hive. More and dedicated experiments are needed to tackle this question, in particular given that the influence of light conditions onto learning has been analysed in several insect species but range from improvement (Yarali et al. 2008) to no change (Matsumoto and Mizunami 2004; Sato et al. 2007) to reduction of learning performance (this paper), suggesting a species-specific trait.
Adaptive and ecological significance

There has been a long discussion since the experiments done by Wahl in the 1930s (Wahl 1932; Wahl 1933) as to whether there is a true circadian rhythmicity in honey bees or whether the bees "just" learn the time of day when food is available. The existence of an endogenous clock was then shown several decades later not only by the identification of the respective genes (Toma et al. 2000) but also by behavioural experiments which show its control on locomotion, time sensing or food anticipatory behaviour (for a review, see Moore 2001). We confirmed that bees can be trained to visit a feeder at a particular time of day. However, we also show that this training has no impact on the circadian fluctuation in learning performance: learning remains best in the morning.

This also concurs with a higher level of foraging accuracy of bees trained to a morning food source in comparison to bees trained to an afternoon food source (Moore et al. 1989). Therefore, our results cannot be explained by an immediate behavioural adaptation. Indeed the tendency for food anticipatory behaviour might be one of the evolutionary driving forces in the interaction between flowers and bees.

We propose that the advantage is energetic, under the assumption that high learning performance is energetically costly (Mery and Kawecki 2003). In this view, the need to learn new odours would be reduced during the afternoon because there are fewer flowering plants at that time. It was shown by Kleber (Kleber 1935) that most flowers she investigated blossom and secret nectar and pollen during the morning, an observation that was repeatedly confirmed (Jaxtheimer 1949; Maurizio 1953; Pesti 1976; Mačukanović and Blaženčić 1998). This is also true for aphid sucrose secretion, the so-called honey dew, which is an important food source for bees (Gleim 1984). We therefore hypothesise that the increased learning performance has co-evolved with the plant's nectar and pollen secretion.

But what is the evolutionary force that pushes this coevolution to the morning hours rather than any other time of the day? The bees entrained to food times in this study showed the same behaviour described elsewhere (Forel 1910; Moore et al. 1989; Moore and Doherty 2009): they were already waiting at their feeding place prior to the entrained feeding time. We therefore speculate that it might be evolutionarily advantageous to be the "early bee" and to "catch" the flower in order to outcompete possible competitors such as butterflies, flies and conspecifics of other hives. Thus, bees and flowers may have evolved an arms race for earlier times of day, bounded by dawn on one side and by productivity on the other. This tendency might be strengthened by other factors, e.g. that the bees perform better after resting (Hussaini et al. 2009) or that nectar production might 
accumulate overnight (Kleber 1935), factors that could act as preadaptation in evolutionary terms.

If this hypothesis was true, we would expect learning performance to increase already before dawn. Indeed all our data show that honey bees' learning performance reaches its lowest point between ZT15 and ZT21 and that the learning performance rises again afterwards. At their first foraging trip, bees have to learn the most profitable food source for that day which they can harvest afterwards. The temporal optimum of the plants' nectar and pollen production and the shift to earlier arrival by competitive pressure result in a common ecological niche.

A. mellifera appeared about 1 mya and colonised its present-day range with a number of subspecies about 50,000 to 100,000 years ago (Ruttner 2003). During the last glacial stages of our glacial age, plants and bees had to retreat repeatedly into regions with a warmer climate or insular areas with better survival conditions (Ellenberg 1996; Schroeder 1998; Ruttner 2003). This length of time should be sufficient to develop a tight plant - xinsect relationship. If this coevolution between plants and honey bees favours morning nectar and pollen secretion, why do not all plants exhibit the same diurnal rhythm? Not all flowers are pollinated by honey bees: e.g. Silene spp. and Saponaria officinalis both show a peak in nectar secretion at night and are pollinated by nocturnal butterflies and hawk moths (Baker 1961; Witt et al. 1999; Wolff et al. 2006). Moths have a quite good appetitive memory (Daly et al. 2001) and can learn odours. If our hypothesis is correct and moths learn to associate floral odorants with rewarding flowers, we would predict that they exhibit their best learning performance during the early night. A possible candidate moth for Central Europe would be Autographa gamma (Esche 1996). If our hypothesis is right, specialised insect - plant relationships would not be under the evolutionary pressure for early morning hours. These include the highly specific relationship between the sexually deceptive orchids of the genus Ophrys and their pollinators (Kullenberg 1961; Borg-Karlson 1990; Schiestl et al. 1999). More research is needed to study these interactions.

Our findings demonstrate that honey bees learn best early in the morning and propose an evolutionary scenario that would explain this finding. Our results also provide an important aspect to consider in designing future learning experiments: circadian fluctuations need to be accounted for.

\footnotetext{
Acknowledgements We thank Wilhelm Schönherr and Isabel Seier for help with the experiments, Wolfram Kutsch for helpful discussions and useful comments and two anonymous referees for helpful suggestions. This study was funded by the Deutsche Forschungsgemeinschaft (DFG) and the University of Konstanz. The funders had no role in study design, data collection and analysis, decision to publish, or preparation of the manuscript. The experiments comply with the current laws of Germany.
}

Conflicts of interest The authors declare that they have no conflicts of interest.

Open Access This article is distributed under the terms of the Creative Commons Attribution Noncommercial License which permits any noncommercial use, distribution, and reproduction in any medium, provided the original author(s) and source are credited.

\section{References}

Arenas A, Fernandez VM, Farina WM (2007) Floral odor learning within the hive affects honeybees' foraging decisions. Naturwissenschaften 94:218-222

Aschoff J (1981) Biological rhythms. Plenum, New York

Baker HG (1961) The adaptation of flowering plants to nocturnal and crepuscular pollinators. Q Rev Biol 36:64-73

Beier W (1968) Beeinflussung der inneren Uhr der Bienen durch Phasenverschiebung des Licht-Dunkel-Zeitgebers. Z Bienenforsch 9:356-378

Beier W, Lindauer M (1970) Der Sonnenstand als Zeitgeber für die Biene. Apidologie 1:5-28

Beling I (1929) Über das Zeitgedächtnis der Bienen. J Comp Physiol A 9:259-338

Bennett MF, Renner M (1963) Collecting performance of honey bees under laboratory conditions. Biol Bull 125:416-430

Beutler R (1930) Biologisch-chemische Untersuchungen am Nektar von Immenblumen. J Comp Physiol A 12:72-176

Bitterman ME, Menzel R, Fietz A, Schäfer S (1983) Classical conditioning of proboscis extension in honeybees (Apis mellifera). J Comp Psychol 97:107-119

Borg-Karlson AK (1990) Chemical and ethological studies of pollination in the genus Ophrys (Orchidaceae). Phytochemistry 29:1359-1387

Chaudhury D, Colwell CS (2002) Circadian modulation of learning and memory in fear-conditioned mice. Behav Brain Res 133:95-108

Daan S (2000) Learning and circadian behavior. J Biol Rhythms $15: 296-299$

Daly KC, Durtschi ML, Smith BH (2001) Olfactory-based discrimination learning in the moth, Manduca sexta. J Insect Physiol 47:375-384

Decker S, McConnaughey S, Page TL (2007) Circadian regulation of insect olfactory learning. Proc Natl Acad Sci USA 104:1590515910

Dyer FC, Dickinson JA (1994) Development of sun compensation by honeybees: how partially experienced bees estimate the sun's course. Proc Natl Acad Sci USA 91:4471-4474

Ellenberg H (1996) Vegetation Mitteleuropas mit den Alpen in ökologischer, dynamischer und historischer Sicht, 5., stark veränd. und verb. Aufl.. edn. Ulmer, Stuttgart

Esche T (1996) Konkurrieren Nachtschmetterlinge um Blüten? Untersuchungen zu Nischentrennung und Bestäubungseffektivität (Insecta, Lepidoptera). Neue Entomol Nachr 35:1-194

Fabbri M, Natale V, Adan A (2008) Effect of time of day on arithmetic fact retrieval in a number-matching task. Acta Psychol 127:485-490

Farina WM, Gruter C, Diaz PC (2005) Social learning of floral odours inside the honeybee hive. Proc R Soc Lond B 272:1923-1928

Farina WM, Grüter C, Acosta L, Mc Cabe S (2007) Honeybees learn floral odors while receiving nectar from foragers within the hive. Naturwissenschaften 94:55-60

Fernández VM, Arenas A, Farina WM (2009) Volatile exposure within the honeybee hive and its effect on olfactory discrimination. J Comp Physiol A 195:759-768 
Folkard S (1975) Diurnal variation in logical reasoning. Br J Psychol $66: 1-8$

Folkard S, Monk TH (1980) Circadian rhythms in human memory. Br J Psychol 71:295-307

Forel A (1910) Das Sinnesleben der Insekten: eine Sammlung von experimentellen und kritischen Studien über Insektenpsychologie. E. Reinhardt, München

Frisch B, Aschoff J (1987) Circadian rhythms in honeybees: entrainment by feeding cycles. Physiol Entomol 12:41-49

Fuchikawa T, Shimizu I (2007) Effects of temperature on circadian rhythm in the Japanese honeybee, Apis cerana japonica. J Insect Physiol 53:1179-1187

GeneralAviation (2009) Sunrise-sunset. http://www.generalaviation. de/index.shtml. Accessed 2009

Gleim K-H (1984) Die Honigtautracht: Wirtspflanzen; Lachniden und Lecanien; Ameisen, ihre Bestimmung, Vermehrung und Nestschutz; Tautrachtbeobachtung und -beurteilung; Möglichkeiten der Trachtvorhersage, vol 2, 1st edn. Delta Verlag, Sankt Augustin

Guerrieri F, Schubert M, Sandoz JC, Giurfa M (2005) Perceptual and neural olfactory similarity in honeybees. PLoS Biol 3:e60

Hamm U, Chandrashekaran MK, Engelmann W (1975) Temperature sensitive events between photoreceptor and circadian clock? $\mathrm{Z}$ Naturforsch C 30:240-244

Buttel-Reepen HBv (1900) Sind die Bienen Reflexmaschinen? Arthur Georgi, Leipzig

Hoover SER, Keeling CI, Winston ML, Slessor KN (2003) The effect of queen pheromones on worker honey bee ovary development. Naturwissenschaften 90:477-480

Hussaini SA, Bogusch L, Landgraf T, Menzel R (2009) Sleep deprivation affects extinction but not acquisition memory in honeybees. Learn Mem 16:698-705

Jaxtheimer R (1949) Die Ausnutzung der heimischen Flora durch die Bienen. Arch Bienenkd 25:17-30

Kaiser W (1988) Busy bees need rest, too-behavioral and electromyographical sleep signs in honeybees. J Comp Physiol A $163: 565-584$

Kleber E (1935) Hat das Zeitgedächtnis der Bienen biologische Bedeutung? J Comp Physiol A 22:221-262

Kleitman N (1933) Studies on the physiology of sleep: VIII. Diurnal variation in performance. Am J Physiol 104:449-456

Koltermann R (1971) 24-Std-Periodik in der Langzeiterinnerung an Duft- und Farbsignale bei der Honigbiene. J Comp Physiol A 75:49-68

Konopka RJ, Benzer S (1971) Clock mutants of Drosophila melanogaster. Proc Natl Acad Sci USA 68:2112-2116

Kullenberg B (1961) Studies in Ophrys pollination. Almqvist \& Wiksell, Stockholm

Lindauer M (1960) Time-compensated sun orientation in bees. Cold Spring Harb Symp Quant Biol 25:371-377

Lunney GH (1970) Using analysis of variance with a dichotomous dependent variable: an empirical study. J Educ Meas 7:263269

Lyons LC, Roman G (2009) Circadian modulation of short-term memory in Drosophila. Learn Mem 16:19-27

Lyons LC, Rawashdeh O, Katzoff A, Susswein AJ, Eskin A (2005) Circadian modulation of complex learning in diurnal and nocturnal Aplysia. Proc Natl Acad Sci USA 102:12589-12594

Mačukanović M, Blaženčić Ž (1998) Diurnal and seasonal dynamics of nectar secretion of some species in the family Lamiaceae. Acta Vet 48:173-183

Matsumoto Y, Mizunami M (2004) Context-dependent olfactory learning in an insect. Learn Mem 11:288-293

Maurizio A (1953) Weitere Untersuchungen an Pollenhöschen. Beitrag zur Erfassung der Pollentrachtverhältnisse in verschiedenen Gegenden der Schweiz. Beih Schweiz Bienenztg 2:485-556
Menzel R (1990) Learning, memory, and 'cognition' in honey bees. In: Kesner RP, Olton DS (eds) Neurobiology of comparative cognition. Erlbaum, Hillsdale, New Jersey, pp 237-292

Mery F, Kawecki TJ (2003) A fitness cost of learning ability in Drosophila melanogaster. Proc R Soc Lond B Biol Sci 270:2465-2469

Moore D (2001) Honey bee circadian clocks: behavioral control from individual workers to whole-colony rhythms. J Insect Physiol 47:843-857

Moore D, Doherty P (2009) Acquisition of a time-memory in forager honey bees. J Comp Physiol A 195:741-751

Moore D, Rankin MA (1983) Diurnal changes in the accuracy of the honeybee foraging rhythm. Biol Bull 164:471-482

Moore D, Rankin MA (1985) Circadian locomotor rhythms in individual honeybees. Physiol Entomol 10:191-197

Moore D, Siegfried D, Wilson R, Rankin MA (1989) The influence of time of day on the foraging behavior of the honeybee, Apis mellifera. J Biol Rhythms 4:305-325

Pahl M, Zhu H, Pix W, Tautz J, Zhang S (2007) Circadian timed episodic-like memory - a bee knows what to do when, and also where. J Exp Biol 210:3559-3567

Pankiw T (2004) Brood pheromone regulates foraging activity of honey bees (Hymenoptera: Apidae). J Econ Entomol 97:748-751

Pankiw T, Page RE, Fondrk MK (1998) Brood pheromone stimulates pollen foraging in honey bees (Apis mellifera). Behav Ecol Sociobiol 44:193-198

Pankiw T, Roman R, Sagili RR, Zhu-Salzman K (2004) Pheromonemodulated behavioral suites influence colony growth in the honey bee (Apis mellifera). Naturwissenschaften 91:575-578

Pelz C, Gerber B, Menzel R (1997) Odorant intensity as a determinant for olfactory conditioning in honeybees: roles in discrimination, overshadowing and memory consolidation. J Exp Biol 200:837-847

Percival M (1950) Pollen presentation and pollen collection. New Phytol 49:40-63

Percival M (1947) Pollen collection by Apis mellifera. New Phytol 46:142-165

Pesti J (1976) Daily fluctuations in the sugar content of nectar and periodicity of secretion in the Compositae. Acta Agro Acad Sci Hung 25:5-17

Prabhu C, Cheng K (2008a) One day is all it takes: circadian modulation of the retrieval of colour memories in honeybees. Behav Ecol Sociobiol 63:11-22

Prabhu C, Cheng K (2008b) Recency preference of odour memory retrieval in honeybees. Behav Ecol Sociobiol 63:23-32

R Development Core Team (2008) R: a language and environment for statistical computing. R Foundation for Statistical Computing, Vienna, Austria. ISBN 3-900051-07-0

Rawashdeh O, de Borsetti NH, Roman G, Cahill GM (2007) Melatonin suppresses nighttime memory formation in zebrafish. Science 318:1144-1146

Renner M (1960) The contribution of the honey bee to the study of time-sense and astronomical orientation. Cold Spring Harb Symp Quant Biol 25:361-367

Rose R, Menzel R (1981) Luminance dependence of pigment color discrimination in bees. J Comp Physiol A 141:379-388

Rubin EB, Shemesh Y, Cohen M, Elgavish S, Robertson HM, Bloch G (2006) Molecular and phylogenetic analyses reveal mammalian-like clockwork in the honey bee (Apis mellifera) and shed new light on the molecular evolution of the circadian clock. Genome Res 16:1352-1365

Ruttner F (2003) Naturgeschichte der Honigbienen, 2. Aufl.. edn. Kosmos, Stuttgart

Sagili RR, Pankiw T (2009) Effects of brood pheromone modulated brood rearing behaviors on honey bee (Apis mellifera L.) colony growth. J Insect Behav 22:339-349 
Sato C, Matsumoto Y, Watanabe H, Mizunami M (2007) Contextual learning in cockroaches monitored by extracellular recording of salivary neurons. Comp Biochem Physiol B Biochem Mol Biol 148:343-343

Schiestl FP, Ayasse M, Paulus HF, Lofstedt C, Hansson BS, Ibarra F, Francke W (1999) Orchid pollination by sexual swindle. Nature 399:421-422

Schmeil O, Fitschen J, Seybold S (2009) Flora von Deutschland und angrenzender Länder: ein Buch zum Bestimmen der wild wachsenden und häufig kultivierten Gefäßpflanzen, 94, unveränd. Aufl.. edn. Quelle \& Meyer, Wiebelsheim

Schmidt C, Collette F, Cajochen C, Peigneux P (2007) A time to think: circadian rhythms in human cognition. Cogn Neuropsychol 24:755-789

Schroeder F-G (1998) Lehrbuch der Pflanzengeographie. Quelle \& Meyer, Wiesbaden

Shemesh Y, Cohen M, Bloch G (2007) Natural plasticity in circadian rhythms is mediated by reorganization in the molecular clockwork in honeybees. FASEB J 21:2304-2311

Thiele C (2009) Apper.de. http://sonne.apper.de/. Accessed 2009

Toma DP, Bloch G, Moore D, Robinson GE (2000) Changes in period mRNA levels in the brain and division of labor in honey bee colonies. Proc Natl Acad Sci USA 97:6914-6919

Towne WF (2008) Honeybees can learn the relationship between the solar ephemeris and a newly-experienced landscape. J Exp Biol 211:3737-3743

Towne WF, Moscrip H (2008) The connection between landscapes and the solar ephemeris in honeybees. J Exp Biol 211:3729-3736
Vergoz V, Roussel E, Sandoz JC, Giurfa M (2007) Aversive learning in honeybees revealed by the olfactory conditioning of the sting extension reflex. Plos One 2:e288

von Frisch K (1940) Die Tänze und das Zeitgedächtnis der Bienen im Widerspruch. Naturwissenschaften 28:65-69

von Frisch K (1950) Die Sonne als Kompaß im Leben der Bienen. Cell Mol Life Sci 6:210-221

von Frisch K (1965) Tanzsprache und Orientierung der Bienen. Springer, Berlin

Wahl O (1932) Neue Untersuchungen über das Zeitgedächtnis der Bienen. J Comp Physiol A 16:529-589

Wahl O (1933) Beitrag zur Frage der biologischen Bedeutung des Zeitgedächtnisses der Bienen. J Comp Physiol A 18:709-717

Warrant E, Porombka T, Kirchner WH (1996) Neural image enhancement allows honeybees to see at night. Proc R Soc Lond B Biol Sci 263:1521-1526

Winston ML, Slessor KN (1992) The essence of royalty: honey bee queen pheromone. Am Sci 80:374-385

Witt T, Jürgens A, Geyer R, Gottsberger G (1999) Nectar dynamics and sugar composition in flowers of Silene and Saponaria species (Caryophyllaceae). Plant Biol 1:334-345

Wolff D, Witt T, Juergens A, Gottsberger G (2006) Nectar dynamics and reproductive success in Saponaria officinalis (Caryophyllaceae) in southern Germany. Flora (Jena) 201:353364

Yarali A, Mayerle M, Nawroth C, Gerber B (2008) No evidence for visual context-dependency of olfactory learning in Drosophila. Naturwissenschaften 95:767-774 